\title{
Why Does Covid-19/SARS-CoV2 Spread all Over the Whole World? Is Migration Bat Wrong or Bird Wrong?
}

\author{
Jia-Ping $\mathbf{W u}^{*}$ \\ Department of Internal Medicine, National Taipei University of Nursing and Health Sciences, Taiwan
}

*Corresponding author: Jia-Ping Wu, Department of Internal Medicine, National Taipei University of Nursing and Health Sciences, Research Center for Healthcare Industry Innovation, Taiwan.

To Cite This Article: Jia-Ping Wu, Why Does Covid-19/SARS-CoV2 Spread all Over the Whole World? Is Migration Bat Wrong or Bird Wrong? Am J Biomed Sci \& Res. 2020 - 11(3). AJBSR.MS.ID.001640. DOI: 10.34297/AJBSR.2020.11.001640.

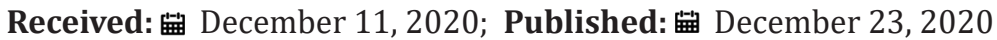

\begin{abstract}
This type of lung virus infection tends to spread quickly. This virus is a highly contagious disease. Although early analysis of the disease indicated that the virus first appeared in Wuhan, this claim has not been fully confirmed by researchers. COVID-19 may be closely related to the spread of contact between humans and animals. The possibility of the virus is a mutational infection. The host of viruses that are currently believed to infect humans is bats. This is different from the 2002 new type of coronavirus, also known as SARS or atypical pneumonia virus, but it comes from the same SARS-CoV and becomes the 2019 new type of coronavirus (SARS-CoV2). However, novel SARS-CoV2 is from bats migration. The infection is caused by contact between humans and bats, it is worthy of discussion.
\end{abstract}

Keywords: COVID-19; Novel SARS-coV2; Bats Migration; Mutational Infection

\section{Introduction}

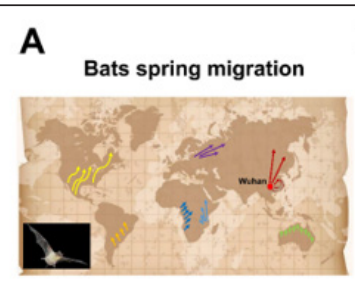

C

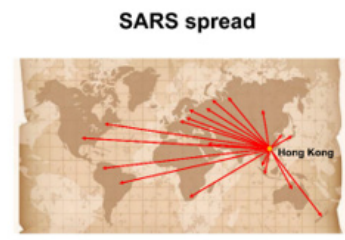

B

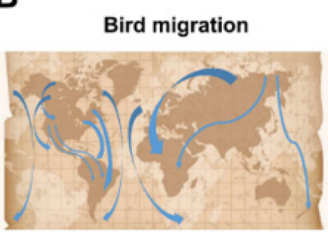

D

COVID-19 expand

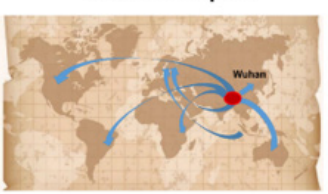

Figure 1: The relationship of bat migration, bird migration and COVID-19?

a) Hoary bats make annual long-distance migrations between Mexico and Canada (yellow lines), South American Bat (Noctilio albiventris) (orange lines), Little Collar Fruit Bat (Myonycteris torquate) (light blue lines), Hammerhead Fruit Bat (Hypsignathus monstrosus) (dark blue lines), London Vampire bats (Desmodus Rotundus) (purple lines), Chinese chrysanthemum bat (Rhinolophus sinicus) (red lines), Austria grey-headed flying fox (Pteropus poliocephalus) (green lines).

b) Birds migrate for the winter from Northern to Southern (blue lines).

c) SARS-CoV-1 coronaviruses from the 2002-03 SARS outbreak in Hong Kong and transmission over the whole world (red lines).

d) SARS-like beta-coronaviruses causes the novel coronavirus SARS-CoV-2 from the COVID-19 epidemic in Wuhan, China (blue lines). 
SARS and COVID-19 are both occur from bats because they have the same gene codes as bats genes. There is evidence that the virus was leaked from the Wuhan Institute of Virology, and it is not clear that Wuhan is the source of the virus. However, the virus SARS, which can infect humans, is hosted by bats migration. Why does COVID-19/SARS-CoV2 spread all the whole world? Is migration bat wrong or bird wrong? Bats migration is a presumed reservoir of diverse coronaviruses (CoVs) such as SARS and COVID-19. The identification of infections coronaviruses was provided for genetic variations, this virus to be named bat SARS CoV (bat-SARS-CoV) permitting efficient animal-to-human transmissions from Chinese horseshoe bats in Hong Kong in 2002, and a SARS-CoV-related virus from human-to-human transmissions in Wuhan in 2019 proposes be named COVID-19 [1]. To identify the host and geographic regions of COVID-19 evolutionary diversity in China could help target bat$\mathrm{CoV}$ discovery for zoonotic disease surveillance. Bats are best known for their long-distance migrations, like bird migration, but bat can't long-distance foreign migration, birds can do this (Figure 1). However, from the perspective of evolutionary biology, by comparing gene maps, the closest relative of the new coronavirus is found in bats and is named SARS-CoV2 [2]. However, bats can't handle winter. Some bats will migrate before winter to deal with the freezing conditions and loss of food and spring migrates from South to North for food to give birth to feeding young bats (Figure 1A). This behavior of migration bats seems to be synchronized with seasonal temperature changes [3]. Some bats arrived too early in their summer habitat may experience sudden cold and even freeze to death [4].

In temperate regions, bats need to tackle this challenge. However, not only bats face winter. Like bird migration from North to South, but bats migration was from South to North (Figure 1B). Bird is one species that travels across the world to migrate. The bird migration to south keeps warm, and feedback to Northern The epidemic situation from bird infection is maned by the avian influenza virus [5]. The transmission in the whole world is an important point of difference between the two viruses. The range of symptoms for the two viruses is similar, severe disease appears to be different [6]. Related SARS-like viruses were shared and expand in Hong Kong, China, but COVID-19/SARS-CoV2 spread all the whole world from Wuhan in China (Figures 1C \& 1D). Did the SARS-CoV 2 virus originate in China outside Wuhan? There is no doubt that the virus is a highly contagious disease. It has infected more than 4.2 million people worldwide and causes nearly 290,000 deaths [7]. There is strong indirect evidence that SARS virus did not actually originate in Wuhan. Obviously, the virus can change its mutation rate in 2019 winter after bat spring migration [8,9].

\section{Acknowledgements}

N/A.

\section{Conflict of Interest}

No conflict of interest.

\section{References}

1. Yi F, Kai Z, Zheng LS, Peng Z (2019) Bat Coronaviruses in China. Viruses 11: 210.

2. Swelum AA, Shafi ME, Albaqami NM, Mohamed T El-Saadony, Ahmed Elsify, et al. (2020) COVID-19 in Human, Animal and Environment: A Review. Front Vet Sci 7: 578.

3. Ruscena W, Laura LH, Jon C, Rodrigo A Medellín, Paul Cryan, et al. (2013) Moving across the border: modeling migratory bat populations: Ecosphere 4: 1-16.

4. Alice L, Ben H, Kevin JO, Guangjian Zhu, Libiao Zhang, et al. (2020) Origin and cross-species transmission of bat coronaviruses in China. Nat Commun 11: 4235.

5. Montecino Latorre D, Goldstein T, Gilardi K (2020) Reproduction of East- African bats may guide risk mitigation for coronavirus spillover. One Health Outlook.

6. Dhama K, Khan S, Tiwari R, Shubhankar Sircar, Sudipta Bhat, et al. (2020) Coronavirus Disease 2019-COVID-19. Clin Microbiol Rev 33(4).

7. Feijó A, Wang Y, Sun J, Lin Xia, Qisen Yang, et al. (2019) Research trends on bats in China: A twenty-first century review. Mammalian biology 98 . 163-172.

8. Schlottau K, Rissmann M, Graaf A, Jacob Schön, Julia Sehl, et al. (2020) SARS-CoV-2 in fruit bats, ferrets, pigs, and chickens: an experimental transmission study. Lancet Microbe 1(5): 218-225.

9. Kinsella CM, Santos PD, Postigo Hidalgo I, Alba Folgueiras González, Tim Casper Passchier, et al. (2020) Preparedness needs research: How fundamental science and international collaboration accelerated the response to COVID-19. Plos Pathog 9(16): 1008902. 